\title{
The Functional Outcome of Patients Following Spinal Injury in Asia Metropolitans: Does the Prehospital Spine Immobilization Matter?
}

\section{Hsuan An Chen}

Far Eastern Memorial Hospital

\section{Shuo Ting Hsu}

Far Eastern Memorial Hospital

\section{Sang Do Shin}

Seoul National University College of Medicine and Hospital

\section{Sabariah Faizah Jamaluddin}

Universiti Teknologi MARA

\section{Do Ngoc Son}

Bach Mai Hospital

\section{Ki Jeong Hong}

Seoul National University College of Medicine and Hospital

\section{Hideharu Tanaka}

Graduate School of Kokushikan University

\section{Jen Tang Sun}

Far Eastern Memorial Hospital

Wen-Chu Chiang ( $\nabla$ drchiang.tw@gmail.com )

National Taiwan University Hospital

\section{Research Article}

Keywords: Patients, Spinal Injury, Prehospital, Immobilization

Posted Date: July 27th, 2021

DOI: https://doi.org/10.21203/rs.3.rs-724919/v1

License: (c) (i) This work is licensed under a Creative Commons Attribution 4.0 International License. Read Full License 


\section{Abstract}

Prehospital spinal immobilization is a widely used procedure in the emergency medical service (EMS) system worldwide, while the incidence of patients with spinal injury (SI) is relatively low, and unnecessary prehospital spinal immobilization is associated with patient complications. This study aimed to determine the association between prehospital spine immobilization and favorable functional outcomes at hospital discharge among trauma patients with SI. We conducted a retrospective cohort study using the Pan-Asia Trauma Outcomes Study (PATOS) registry data from January 1, 2016, to November 30, 2018. A total of 759 patients with SI were enrolled from 43,752 trauma patients in the PATOS registry during the study period. The subjects had a median age of 58 years ( Q1-Q3,41-72), and 438 (57.7\%) patients had prehospital spine immobilization. Overall, prehospital spinal immobilization was not associated with favorable functional outcomes at discharge in multivariable logistic regression $(\mathrm{aOR}, 1.06 ; 95 \% \mathrm{Cl} 0.62-1.81, \mathrm{p}=0.826)$. However, in the subgroup of cervical $\mathrm{SI}$, prehospital spinal immobilization was associated with favorable functional outcomes at discharge $(\mathrm{aOR}, 3.14 ; 95 \% \mathrm{Cl}$ 1.04-9.50; $p=0.043$ ). Therefore, we suggest that paramedics should be more careful when determining cervical SI and using prehospital immobilization.

\section{Introduction}

Patients with spinal injuries (SIs) following trauma are at risk of spinal cord injuries (SCls) with severe neurological consequences and disability in life, which are estimated in approximately $20 \%$ of these cases ${ }^{1}$. However, the incidence of traumatic SCI differs from region to region, with a relatively low incidence of 16 per million in Western Europe to 40 per million in the United States ${ }^{2}$. The incidence of $\mathrm{SI}$ in the trauma population also varied from $4.58 \%$ in China to all trauma patients ${ }^{3}$ and $9.6 \%$ in Europe in patients following major trauma ${ }^{4}$, while some studies reported only $1-2 \%$ of all trauma patients ${ }^{5}$.

Despite the relatively low incidence of $\mathrm{SI}$ and $\mathrm{SCl}$, prehospital spinal immobilization has been widely adopted worldwide as well as in trauma courses, such as prehospital trauma life support (PHTLS) and advanced trauma life support (ATLS) ${ }^{6,7}$. It aims to minimize further movement of the spine and reduce the risk of secondary injury, but the procedure lacks high-quality evidence of clear benefits in decreasing disability ${ }^{8,9}$ and is associated with complications such as respiratory restriction 10,11 , elevated intracranial pressure ${ }^{12,13}$, pressure ulcers ${ }^{14}$ and changing the results of physical examination ${ }^{15}$ while patients are immobilized. In addition, previous studies also revealed that prehospital immobilization may be associated with higher mortality in patients with penetrating trauma and gun-shot wounds ${ }^{16-18}$.

Due to the growing concerns regarding prehospital spinal immobilization, this study aimed to determine the association between prehospital spinal immobilization and favorable functional outcomes at hospital discharge among adult trauma patients with SI.

\section{Methods}

\section{Study design and setting}

We conducted a retrospective cohort study using a prospectively collected database from the Pan-Asia Trauma Outcomes Study (PATOS), which was a cross-national trauma registry network initiated in 2015 and consists of 33 participating sites from 14 Asian countries, including Australia, Hong Kong, India, Indonesia, Japan, Korea, Malaysia, Philippines, Singapore, Sri Lanka, Taiwan, Thailand, the United Arab Emirates, and Vietnam. Urban areas are covered by all countries ${ }^{19}$. The variables of PATOS include demographics, injury epidemiology, prehospital care, emergency department (ED) and hospital care, injury severity, and clinical outcomes ${ }^{20}$. The PATOS Trauma Database was characterized as an emergency medical service (EMS)based registry. Participation in the PATOS registry was voluntary. Patient's data were recorded in the registry if they were sent to the participating hospitals due to trauma, either from the scene or via interhospital transport. 


\section{Study population}

We analyzed patients with PATOS from January 1, 2016, to November 30, 2018. Eligible patients were transported by EMS, aged $>16$ years, and with SIs. SI was defined as any spinal fracture, dislocation, subluxation, or traumatic disc rupture with or without SCI. The diagnosis was selected using ICD-9 (other paralytic syndromes 344.0-344.9; fracture of vertebral column without mention of SCI 805.0-805.5; fracture of the vertebral column with SCI 806.0-806.6; dislocation of vertebra 839.4; SCI without evidence of spinal bone injury 952.0-952.9) or ICD-10 (fracture of vertebra S12.0-S12.9, S22.0, S32.0, S32.9; dislocation, subluxation of vertebrae, traumatic rupture of intervertebral disc S13.0-S13.1, S23.0-S23.1, S33.0-S33.1; injury of nerves and spinal cord S14.0-S14.9, S24.0-S24.2, S34.0-S34.2) based on the registry data, we excluded patients with preexisting disability (defined as Glasgow Outcome Score [GOS] <4 before the injury), traumatic brain injury (TBI) (defined as traumatic cerebral edema, diffuse/focal TBI, epidural hemorrhage, traumatic subdural hemorrhage, traumatic subarachnoid hemorrhage using ICD-9 854.0, 851.0-852.5; ICD-10 S06.1-S06.9), incomplete data on immobilization, Injury Severity Score (ISS), Revised Trauma Score (RTS) at the ED, functional outcome at discharge or prehospital time interval. We excluded patients with TBI because the prevalence of concomitant TBI in patients with an SI can be as high as $32.5 \%{ }^{21}$, and we could not differentiate whether the disability resulted from TBI or SI.

\section{Definition of exposure}

The key exposures in our study were prehospital immobilization, which was defined as the neck collar and/or backboard used. The basic characteristics of the patients in our study included country, age, sex, mechanism of injury (traffic, fall, others), location of SI (cervical, thoracic, or lumbar spine), and torso injury. Torso injury was defined as injury involving the chest or abdomen, including fractures of the clavicle, rib, pelvis, traumatic pneumothorax, hemothorax, intra-abdominal bleeding, laceration, or contusion of the spleen, liver, or bowel. Data on prehospital management, including spinal immobilization, rescue airway (supraglottic airway or endotracheal tube), the establishment of fluid access either by intravenous line (IV) or by intraosseous line (IO), and scene-to-hospital time (S to H time) were collected. Because one of the major contributing countries (Korea) mostly reported the $\mathrm{S}$ to $\mathrm{H}$ time rather than transport time, we used $\mathrm{S}$ to $\mathrm{H}$ time as variables to maximize the valid value. We used the RTS and ISS as indices of trauma severity. RTS is a physiological triage score using the Glasgow Coma Scale (GCS), systolic blood pressure (SBP), and respiratory rate (RR). The RTS formula was as follows: $\mathrm{RTS}=($ GCS score coded $\times 0.9368)+($ SBP coded $\times 0.7326)+(\text { RR coded } \times 0.2908)^{22}$. ISS was calculated by summing the square of the three highest Abbreviated Injury Scale scores for injuries to different body regions ${ }^{23}$. We divided the ISS score into three groups: $<9$, minor injury; 9-15 defined as moderate injury; and $\geq 16$, severe injury ${ }^{24,25}$. We also collected data from patients who had undergone spine surgery or surgery of other body regions except for the spine. Missing data of the variables were excluded.

\section{Outcome measurements}

The primary outcome was the modified Rankin Scale (mRS) score at discharge. MRS was used to evaluate the functional outcome in patients with stroke at first ${ }^{26}$ and was then applied to measure the disability caused by TBI and general trauma 27-30. No significant disability to moderate disability (mRS 0-3) was defined as favorable functional outcome, and moderately severe disability to death (mRS 4-6) was defined as poor functional outcomes ${ }^{31}$. Subgroup analyses were performed in different subgroups of age ( $<65$ and $\geq 65$ years), RTS ( $<7$ and $\geq 7)$, ISS $(<9, \geq 9)$, and the location of SI (cervical, thoracic, and lumbar regions). We used 65 years old as the cut-off value because it represents the most commonly accepted age to consider a patient as an elderly patient and was used according to the guidelines of the Eastern Association for the

Surgery of Trauma ${ }^{32,33}$. A score of 7 as the cut-off point in RTS and 9 as the cut-off point in ISS were used in previous studies for major trauma $25,34,35$.

\section{Statistical methods}


Continuous variables are reported as mean or median (Q1-Q3), as appropriate. Dichotomous and categorical variables are presented as numbers (percentages). Continuous variables were compared using the Mann-Whitney U test. Categorical and nominal variables were compared using Pearson's chi-square test or Fisher's exact test. We examined the association between prehospital spinal immobilization and favorable functional outcomes using univariate logistic regression and multivariable logistic regression. Variables with $p<0.05$ on univariable logistic regression and the major variable (prehospital spinal immobilization) were selected for multivariable logistic regression analysis using the forced entry method. For subgroup analyses, we also conducted multiple logistic regression using the forced entry method for all variables. Statistical analysis was performed using SPSS version 25.0 (IBM, Armonk, NY, USA). All tests were two-sided, and a p-value of less than 0.05 was considered statistically significant.

\section{Ethics approval and consent to participate}

The PATOS collaboration was approved by the Institutional Review Board of the National Taiwan University Hospital and Far Eastern Memorial Hospital. This study was conducted in accordance with the Declaration of Helsinki (as revised in 2013) and the study proposal and methods were approved by the PATOS Taipei Meeting. The data were anonymized before being released to the authors in 2019. Institutional Review Board of Far Eastern Memorial Hospital waived the need for Informed consent due to the retrospective nature of this study.

\section{Results}

\section{Characteristics of study objects}

From January 1,2016 , to November 30,2018 , a total of 1,573 cases with SIs were extracted from the PATOS registry of 43,752 EMS-transported trauma patients (3.5\% of all cases) using ICD-9 or ICD-10. We further excluded patients aged $<16$ years $(n=30)$, pre-existing disability (GOS 1-3) before the injury $(n=274)$, TBI $(n=136)$, and incomplete data $(n=374)$. The remaining 759 adult patients diagnosed with SI were included in the study, and $438(57.7 \%)$ patients had prehospital spine immobilization. Figure 1 shows a detailed flow diagram of the patients enrolled in the final analysis.

The demographics of the 759 patients with prehospital spinal immobilization are shown in Table 1. The study cohort consisted of patients from four countries, including Korea, Malaysia, Japan, and Vietnam. Korea and Malaysia accounted for $97.1 \%$ of the study group. Injury mainly resulted from traffic accidents and falling accidents, and all patients had blunt injuries. The combination of cervical SI and thoracic or lumbar SI was only $3.1 \%(n=24)$.

Compared to the patients in the non-immobilized group, the patients in the immobilized group were younger (54 vs. 65$)$, had a higher percentage of males (61.4\% vs. $47.0 \%$ ), a higher percentage of traffic accidents ( $52.3 \%$ vs. $27.7 \%$ ), a higher percentage of patients who received prehospital fluid management (9.8\% vs. 1.9\%), higher percentage of cervical SI (33.6\% vs. $16.8 \%)$, lower percentage of lumbar SI (47.9\% vs. $59.5 \%)$, higher percentage of torso injury (30.6\% vs. $11.8 \%)$, higher percentage of RTS $<7$ (5\% vs. $2.2 \%)$, higher percentage of ISS score $9-15(31.3 \%$ vs. $16.5 \%)$ and $\geq 16(12.1 \%$ vs. $8.7 \%)$, higher percentage of patients who underwent spine surgery $(11.4 \%$ vs. $3.4 \%)$, and other operations $(16.7 \%$ vs. $7.5 \%)$.

\section{Association between prehospital spinal immobilization and favorable functional outcome}

For the primary outcome of the association between prehospital spinal immobilization and favorable functional outcome, the demographics and the results of univariable and multivariable logistic regression are shown in Table 2. In univariable logistic regression, prehospital spinal immobilization was not significantly associated with favorable functional outcomes (OR, 0.66; 95\% Cl 0.42-1.02; $\mathrm{p}=0.061$ ). Different countries, age, sex, prehospital fluid management, lumbar SI, torso injury, RTS, ISS 9-15, and ISS $\geq 16$ was significantly associated with favorable functional outcomes in univariable logistic regression and were selected as adjusting confounding factors in further multivariable logistic regression. In multivariable logistic regression, prehospital spinal immobilization was not associated with favorable functional outcomes (aOR, 1.06; $95 \% \mathrm{Cl} 0.62-1.81 ; \mathrm{p}=0.826$ ). Different countries (compared to Korea) (Malaysia aOR, 0.37; 95\% $\mathrm{Cl} 0.20-0.71 ; \mathrm{p}=0.002$ ), 
prehospital fluid management (aOR, $0.39 ; 95 \% \mathrm{Cl} 0.19-0.84)$, ISS 9-15 (aOR, 0.41; 95\% Cl 0.24-0.72; $\mathrm{p}=0.002)$, ISS $\geq 16$ (aOR, $0.35 ; 95 \% \mathrm{Cl} 0.17-0.72 ; \mathrm{p}=0.004)$, and patients who underwent spine surgery (aOR, $0.21 ; 95 \% \mathrm{Cl} 0.11-0.41 ; \mathrm{p}<0.001)$ were associated with worse functional outcomes. Only RTS $\geq 7$ was associated with favorable functional outcomes (aOR, 3.41; $95 \% \mathrm{Cl} 1.41-8.25 ; \mathrm{p}=0.007)$.

\section{Subgroup analysis}

In the subgroup analysis (Figure 2), we found that prehospital spinal immobilization was associated with favorable functional outcomes in the subgroup of cervical SI (aOR, 3.14; $95 \% \mathrm{Cl} 1.04-9.50 ; p=0.043)$, but not in the subgroup ISS $<9$, ISS $\geq 9$, RTS $\geq 7$, thoracic SI, and lumbar SI. Unfortunately, multivariable logistic regression could not be performed due to the limited number of patients in subgroup RTS $<7$.

\section{Discussion}

In this cross-national retrospective cohort study from January 1, 2016, to November 30, 2018, we found that prehospital spinal immobilization was not associated with favorable functional outcomes at discharge in all EMS-transported patients with Sl; however, in the subgroup of cervical SI, the procedure still mattered. There was a significant association between prehospital spinal immobilization and favorable functional outcomes at discharge. Our study has several strengths. First, this was a cross-national study in Asia with different EMS systems. Hence, the results may be applicable to other Asian populations. Second, we excluded preexisting disability before injury and TBI to minimize the effect on functional outcome at discharge and to focus more on the impact of SI.

The benefit of spinal immobilization came from indirect and low evidence that numerous studies found that delayed diagnosis of SI without immobilization was correlated with worse disability ${ }^{36-38}$. Toscana et al. ${ }^{38}$ conducted a case series of 123 patients with blunt SI and found that $32(26 \%)$ patients had major neurological deterioration between the time of injury and the time of admission. Of these 32 patients, 19 (59\%) had no immobilization, suggesting that neurological deterioration resulted from not being immobilized. Meanwhile, Hauswald et al. ${ }^{39}$ retrospectively reviewed patients with traumatic SI from the USA and Malaysia, where the former had prehospital spinal immobilization, but the latter did not have prehospital spinal immobilization in all patients. The results revealed that non-immobilized Malaysian patients had a less neurologic disability $(\mathrm{OR}, 2.03 ; 95 \% \mathrm{Cl} 1.03-3.99 ; \mathrm{p}=0.04)$. However, the study was criticized by some points, such as patients who died in the scene or transportation were excluded, no matching of the patient's injury severity, and relatively small sample size. In our study, we did not exclude patients with traumatic out-of-hospital cardiac arrest, and we performed a subgroup analysis to match the injury severity of patients.

In the subgroup analysis of our study, there was a statistically significant association between prehospital spinal immobilization and favorable functional outcome when limited to patients with cervical SI. Excluding patients with TBI may be a cause. The prevalence of concomitant TBI in patients with an $\mathrm{SI}$ was $32.5 \%(95 \% \mathrm{Cl} 10.8-59.3 \%)$ and $40.4 \%(95 \% \mathrm{Cl}$ $33.0-48.0 \%$ ) in patients with cervical $\mathrm{SI}^{21}$. Severe $\mathrm{TBI}$ can cause severe functional disability or death; approximately $38 \%$ of patients die ${ }^{40}$ and, as estimated, $43 \%$ are discharged with long-term disability ${ }^{41}$. Moreover, spinal immobilization could also increase intracranial cerebral pressure in immobilized patients, which could worsen the situation of TBI ${ }^{12}$. Excluding patients with concomitant TBI decreased the influence of brain injury and helped us focus on the effects of SCl and SI.

The incidence of SI in our study was 3.5\% in all EMS-transported trauma patients, which was similar to a previous study from China with an incidence of $4.58 \%$ in the trauma population ${ }^{3}$. The percentage of patients with cervical SI and other locations of SI were also similar to those reported in previous studies 3,42 , indicating the generalizability of our findings. The incidence data for Europe and Canada were relatively high, at $9.6 \%$ and $23.2 \%$, respectively 4,42 , which may be due to the study population with polytrauma and higher severity in their studies. The leading causes of SI were falls (47.3\%) and traffic accidents (41.9\%), which is consistent with previous studies ${ }^{2,43}$. The rate of cervical SI combined with thoracic or lumbar SI 
in our study was $3.1 \%$, which was lower than previous studies (approximately $10 \%$ ) ${ }^{4,6}$. Patients with lower trauma severity in our study may have been the cause.

In patients in the immobilized group, statistically significant higher trauma severity (ISS, RTS), higher percentage of combined torso injury, prehospital fluid management, and SI were noted than non-immobilized groups. It is reasonable that severely injured patients would receive more treatment at the scene. Subgroup analysis using ISS and RTS was performed to reduce the impact of injury severity, and the association between favorable functional outcome and prehospital spinal immobilization was not significant in the subgroup with ISS $<9$, ISS $\geq 9$, and RTS $\geq 7$. The scene-to-hospital time was not significantly different between the immobilized and non-immobilized groups, although the immobilized group received more treatment out of the hospital. This might be due to the familiarity of the procedure from paramedics, and only $42 \%(\mathrm{~N}=184)$ of patients received full spine immobilization in the immobilized group.

\section{Limitation}

There are some limitations to this study. First, this retrospective study had to address the problem of missing data. Some countries did not record some confounding variables, and we had to exclude them from the analysis, which may have caused selection bias. Although we included many variables in the logistic regression analysis, other unknown factors could influence the functional outcomes, such as limited prehospital information from EMS, the quality of each EMS team, bystander management of the patients, the quality of in-hospital care, and subsequent rehabilitation programs. These data cannot be included in our analysis because of incomplete data or non-recording of the variables in the registry. Second, the registry data of PATOS were voluntary and could not be considered a representative sample of the included countries. Third, the sample size was relatively small. However, considering the relatively low incidence rate of SI and SCl, we believe that these findings are still informative to the knowledge gap.

\section{Conclusion}

Prehospital spinal immobilization was not associated with favorable functional outcomes in traumatic patients with Sl; however, subgroup analysis revealed that it may be beneficial for patients with cervical SI without TBI. Based on our findings, we suggest that paramedics should be more judicious when determining the cervical SI and use prehospital immobilization, and prospective trials may be needed in the future.

\section{Declarations}

\section{Acknowledgements}

The authors acknowledge all participating PATOS sites for excellent collaboration, as well as the data quality assurance of the PATOS coordination center at Seoul National University Hospital, to improve prehospital and in-hospital care for trauma patients in Asia. The authors also like to thank the staff, Dr. Chin-Hao Chang, of the National Taiwan University Hospital Statistical Consulting Unit for help in statistical consultation.

\section{Authors' contributions}

J.T.S. designed the study. S.D.S., S.F.J., D.N.S., K.J.H. and H.T. collected and investigated data source. H.A.C., S.T.H., J.T.S. and W.C.C. carried out analysis and interpretation. H.A.C. and W.C.C. performed the statistical analysis. H.A.C. and S.T.H. drafted the paper. J.T.S. and W.C.C. drafted and supervised the study. All authors reviewed the manuscript. Jen Tang Sun and Wen Chu Chiang take responsibility for the paper.

\section{Competing interests}

There are no competing interests to declare. 


\section{Data availability}

The data that support the findings of this study are available from Pan-Asia Trauma Outcomes Study (PATOS) but restrictions apply to the availability of these data, which were used under license for the current study, and so are not publicly available. Data are however available from the authors upon reasonable request and with permission of PATOS. For more detailed information of PATOS, following website is available, http://lems.re.kr/eng/patos-research/.

\section{Funding}

This study was funded by the Taiwan Ministry of Science and Technology (MOST 108-2314-B-002-130-MY3 and MOST 1052314-B-002-200-MY3 and MOST 109-2314-B-002 -154-MY2). The funders had no role in study design, data collection and analysis, decision to publish, or preparation of the manuscript.

\section{PATOS Clinical Research Network}

Participating Nation Investigators: T.V. Ramakrishnan (India), Sabariah Faiwah Jamaluddin (Malaysia), Hideharu Tanaka (Japan), Bernadett Velasco (Philippines), Ki Jeong Hong (South Korea), Jen Tang Sun (Taiwan), Pairoj Khruekarnchana (Thailand), Saleh Fares LLC (United Arab Emirates), Do Ngoc Son (Vietnam)

Participating Site Investigators: Ramana Rao (GVK EMRI, India), George P. Abraham (Indian Institute of Emergency Medical Services, India), T.V. Ramakrishnan (Sri Ramachandra Medical Center, India), Sabariah Faiwah Jamaluddin (Sungai Buloh Hospital, Malaysia), Mohd Amin Bin Mohidin (Sultanah Aminah Hospital, Malaysia), Al-Hilmi Saim (Seri Manjung Hospital, Malaysia), Lim Chee Kean (Pulau Pinang Hospital, Malaysia), Cecilia Anthonysamy (Serdang Hospital, Malaysia), Shah Jahan Din Mohd Yssof (Kuala Lumpur Hospital, Malaysia), Kang Wen Ji (Sarikei Hospital, Malaysia), Cheah Phee Kheng (Sabah Women and Childrens Hospital, Malaysia), Shamila bt Mohamad Ali (Ampang Hospital, Malaysia), Periyanayaki Ramanathan (Kajang Hospital, Malaysia), Chia Boon Yang (Miri Hospital, Malaysia), Hon Woei Chia (Sarawak General Hospital, Malaysia), Hafidahwati binti Hamad (Queen Elizabeth II Hospital, Malaysia), Samsu Ambia Ismail (Teluk Intan Hospital, Malaysia), Wan Rasydan B. Wan Abdullah (Raja Perempuan Zainab II Hospital, Malaysia), Hideharu Tanaka (Kokushikan University, Japan), Akio Kimura (National Center for Global Health and Medicine Hospital, Japan), Bernadett Velasco (East Avenue Medical Center, Philippines), Carlos D. Gundran (Philippine College of Emergency Medicine, Philippines), Pauline Convocar (Southern Philippines Medical Centre, Philippines), Nerissa G.Sabarre (Pasig City General Hospital, Philippines), Patrick Joseph Tiglao (Corazon Locsin Montelibano Memorial Regional Hospital, Philippines), Ki Jeong Hong (Seoul National Univerisity Hospital, South Korea), Kyoung Jun Song (Boramae Medical Center, South Korea), Joo Jeong (Seoul National Univerisity Bundang Hospital, South Korea), Sung Woo Moon and Joo-yeong Kim (Korea University Ansan Hospital, South Korea), Won Chul Cha (Samsung Medical Center, South Korea), Seung Chul Lee (Dongguk University Ilsan Hospital, South Korea), Jae Yun Ahn (Kyungpook National University Hospital, South Korea), Kang Hyeon Lee (Wonju Severance Christian Hospital, South Korea), Seok Ran Yeom (Pusan National University Hospital, South Korea), Hyeon Ho Ryu (Chonnam National University Hospital, South Korea), Su Jin Kim (Korea University Anam Hospital, South Korea), Sang Chul Kim (Chungbuk National University Hospital, South Korea), Lin-Chen Chiang (National Taiwan University Hospital, Taiwan), Jen Tang Sun (Far Eastern Memorial Hospital, Taiwan), Ruei-Fang Wang (Shin Kong Wu Ho-Su Memorial Hospital, Taiwan), Shang-Lin Hsieh (Mackay Memorial Hospital, Taiwan), Wei-Fong Kao (Taipei City Hospital, Taiwan), Sattha Riyapan (Faculty of Medicine Siriraj Hospital, Thailand), Parinya Tianwibool (Faculty of Medicine Chiangmai University, Thailand), Phudit Buaprasert (Faculty of medicine Vajira hospital, Navamindradhiraj University, Thailand), Osaree Akaraborworn (Prince of Songkla University, Thailand), Omer Ahmed Al Sakaf (Dubai Coorporation for Ambulance Services, United Arab Emirates), Saleh Fares LLC (National Ambulance, United Arab Emirates), Le Bao Huy (Thong Nhat Hospital, Vietnam), Do Ngoc Son (Bach Mai Hospital, Vietnam), Nguyen Van Dai (Viet Tiep Hospital, Vietnam)

\section{References}


1. Sundstrøm, T., Asbjørnsen, H., Habiba, S., Sunde, G. A. \& Wester, K. Prehospital use of cervical collars in trauma patients: a critical review. J Neurotrauma, 31, 531-540 https://doi.org/10.1089/neu.2013.3094 (2014).

2. Lee, B. B., Cripps, R. A., Fitzharris, M. \& Wing, P. C. The global map for traumatic spinal cord injury epidemiology: update 2011, global incidence rate., 52, 110-116 https://doi.org/10.1038/sc.2012.158 (2014).

3. Liu, P. et al. Spinal trauma in mainland China from 2001 to 2007: an epidemiological study based on a nationwide database. Spine (Phila Pa 1976), 37, 1310-1315 https://doi.org/10.1097/BRS.0b013e3182474d8b (2012).

4. Hasler, R. M. et al. Epidemiology and predictors of spinal injury in adult major trauma patients: European cohort study. Eur Spine J, 20, 2174-2180 https://doi.org/10.1007/s00586-011-1866-7 (2011).

5. Kreinest, M., Gliwitzky, B., Goller, S. \& Münzberg, M. Präklinische Immobilisation der Wirbelsäule. Notfall + Rettungsmedizin 19, 41-47, doi:10.1007/s10049-015-0118-5 (2016).

6. Subcommittee, A. T. L. S. American College of Surgeons' committee on trauma, i. A. w. g. Advanced trauma life support 10th edition edn(2018).

7. National Association of Emergency Medical Technicians (U.S.). Pre-Hospital Trauma Life Support Committee., A. C. o. S. C. o. T. PHTLS: Prehospital Trauma Life Support. 9th edition edn, (2018).

8. Hood, N. \& Considine, J. Spinal immobilisaton in pre-hospital and emergency care: A systematic review of the literature. Australas Emerg Nurs J, 18, 118-137 https://doi.org/10.1016/j.aenj.2015.03.003 (2015).

9. Purvis, T. A., Carlin, B. \& Driscoll, P. The definite risks and questionable benefits of liberal pre-hospital spinal immobilisation. Am J Emerg Med, 35, 860-866 https://doi.org/10.1016/j.ajem.2017.01.045 (2017).

10. Totten, V. Y. \& Sugarman, D. B. Respiratory effects of spinal immobilization. Prehosp Emerg Care, 3, 347-352 https://doi.org/10.1080/10903129908958967 (1999).

11. Bauer, D. \& Kowalski, R. Effect of spinal immobilization devices on pulmonary function in the healthy, nonsmoking man. Ann Emerg Med, 17, 915-918 https://doi.org/10.1016/s0196-0644(88)80671-1 (1988).

12. Mobbs, R. J., Stoodley, M. A. \& Fuller, J. Effect of cervical hard collar on intracranial pressure after head injury. ANZ J Surg, 72, 389-391 https://doi.org/10.1046/j.1445-2197.2002.02462.x (2002).

13. Núñez-Patiño, R. A., Rubiano, A. M. \& Godoy, D. A. Impact of Cervical Collars on Intracranial Pressure Values in Traumatic Brain Injury: A Systematic Review and Meta-Analysis of Prospective Studies. Neurocrit Care, 32, 469-477 https://doi.org/10.1007/s12028-019-00760-1 (2020).

14. Ham, W. H., Schoonhoven, L., Schuurmans, M. J. \& Leenen, L. P. Pressure ulcers, indentation marks and pain from cervical spine immobilization with extrication collars and headblocks: An observational study., 47, 1924-1931 https://doi.org/10.1016/j.injury.2016.03.032 (2016).

15. March, J. A., Ausband, S. C. \& Brown, L. H. Changes in physical examination caused by use of spinal immobilization. Prehosp Emerg Care, 6, 421-424 https://doi.org/10.1080/10903120290938067 (2002).

16. Brown, J. B. et al. Prehospital spinal immobilization does not appear to be beneficial and may complicate care following gunshot injury to the torso. J Trauma, 67, 774-778 https://doi.org/10.1097/TA.0b013e3181b5f32e (2009).

17. Haut, E. R. et al. Spine immobilization in penetrating trauma: more harm than good? J Trauma, 68, 115-120 discussion 120 - 111https://doi.org/10.1097/TA.0b013e3181c9ee58 (2010).

18. Vanderlan, W. B. et al. Neurologic sequelae of penetrating cervical trauma. Spine (Phila Pa 1976), 34, 2646-2653 https://doi.org/10.1097/BRS.0b013e3181bd9df1 (2009).

19. Sun, K. M. et al. Comparison of Emergency Medical Services and Trauma Care Systems Among Pan-Asian Countries: An International, Multicenter, Population-Based Survey. Prehosp Emerg Care, 21, 242-251 https://doi.org/10.1080/10903127.2016.1241325 (2017).

20. Kong, S. Y. et al. Pan-Asian Trauma Outcomes Study (PATOS): Rationale and Methodology of an International and Multicenter Trauma Registry. Prehosp Emerg Care, 22, 58-83 https://doi.org/10.1080/10903127.2017.1347224 (2018). 
21. Pandrich, M. J. \& Demetriades, A. K. Prevalence of concomitant traumatic cranio-spinal injury: a systematic review and meta-analysis. Neurosurg Rev, 43, 69-77 https://doi.org/10.1007/s10143-018-0988-3 (2020).

22. Champion, H. R. et al. A revision of the Trauma Score. J Trauma, 29, 623-629 https://doi.org/10.1097/00005373198905000-00017 (1989).

23. Baker, S. P., O'Neill, B., Haddon, W. Jr. \& Long, W. B. The injury severity score: a method for describing patients with multiple injuries and evaluating emergency care. J Trauma, 14, 187-196 (1974).

24. Copes, W. S. et al. The Injury Severity Score revisited. J Trauma, 28, 69-77 https://doi.org/10.1097/00005373198801000-00010 (1988).

25. Rozenfeld, M. et al. ISS groups: are we speaking the same language? Inj Prev, 20, 330-335 https://doi.org/10.1136/injuryprev-2013-041042 (2014).

26. van Swieten, J. C., Koudstaal, P. J., Visser, M. C., Schouten, H. J. \& van Gijn, J. Interobserver agreement for the assessment of handicap in stroke patients., 19, 604-607 https://doi.org/10.1161/01.str.19.5.604 (1988).

27. Chen, C. H. et al. Association between prehospital time and outcome of trauma patients in 4 Asian countries: A crossnational, multicenter cohort study. PLOS Medicine, 17, e1003360 https://doi.org/10.1371/journal.pmed.1003360 (2020).

28. Kohli, A. et al. Factors Associated with Return to Work Postinjury: Can the Modified Rankin Scale Be Used to Predict Return to Work? Am Surg, 82, 95-101 (2016).

29. Momenyan, S. et al. Predictive Validity and Inter-Rater Reliability of the Persian Version of Full Outline of Unresponsiveness Among Unconscious Patients with Traumatic Brain Injury in an Intensive Care Unit. Neurocrit Care, 27, 229-236 https://doi.org/10.1007/s12028-016-0324-0 (2017).

30. Sadaka, F., Patel, D. \& Lakshmanan, R. The FOUR score predicts outcome in patients after traumatic brain injury. Neurocrit Care, 16, 95-101 https://doi.org/10.1007/s12028-011-9617-5 (2012).

31. Rangaraju, S., Haussen, D., Nogueira, R. G., Nahab, F. \& Frankel, M. Comparison of 3-Month Stroke Disability and Quality of Life across Modified Rankin Scale Categories. Interv Neurol, 6, 36-41 https://doi.org/10.1159/000452634 (2017).

32. Bonne, S. \& Schuerer, D. J. Trauma in the older adult: epidemiology and evolving geriatric trauma principles. Clin Geriatr Med, 29, 137-150 https://doi.org/10.1016/j.cger.2012.10.008 (2013).

33. Jacobs, D. G. et al. Practice management guidelines for geriatric trauma: the EAST Practice Management Guidelines Work Group. J Trauma, 54, 391-416 https://doi.org/10.1097/01.Ta.0000042015.54022.Be (2003).

34. Huang, Y. T., Huang, Y. H., Hsieh, C. H., Li, C. J. \& Chiu, I. M. Comparison of Injury Severity Score, Glasgow Coma Scale, and Revised Trauma Score in Predicting the Mortality and Prolonged ICU Stay of Traumatic Young Children: A CrossSectional Retrospective Study. Emergency Medicine International 2019, 5453624, doi:10.1155/2019/5453624 (2019).

35. Jeong, J. H. et al. The new trauma score (NTS): a modification of the revised trauma score for better trauma mortality prediction. BMC Surgery, 17, 77 https://doi.org/10.1186/s12893-017-0272-4 (2017).

36. Davis, J. W., Phreaner, D. L., Hoyt, D. B. \& Mackersie, R. C. The etiology of missed cervical spine injuries. J Trauma, 34, 342-346 https://doi.org/10.1097/00005373-199303000-00006 (1993).

37. Platzer, P. et al. Delayed or missed diagnosis of cervical spine injuries. J Trauma, 61, 150-155 https://doi.org/10.1097/01.ta.0000196673.58429.2a (2006).

38. Toscano, J. Prevention of neurological deterioration before admission to a spinal cord injury unit. Paraplegia, 26, 143150 https://doi.org/10.1038/sc.1988.23 (1988).

39. Hauswald, M., Ong, G., Tandberg, D. \& Omar, Z. Out-of-hospital spinal immobilization: its effect on neurologic injury. Acad Emerg Med, 5, 214-219 https://doi.org/10.1111/j.1553-2712.1998.tb02615.x (1998).

40. McIntyre, A., Mehta, S., Aubut, J., Dijkers, M. \& Teasell, R. W. Mortality among older adults after a traumatic brain injury: a meta-analysis. Brain Inj, 27, 31-40 https://doi.org/10.3109/02699052.2012.700086 (2013). 
41. Selassie, A. W. et al. Incidence of long-term disability following traumatic brain injury hospitalization, United States, 2003. J Head Trauma Rehabil, 23, 123-131 https://doi.org/10.1097/01.Htr.0000314531.30401.39 (2008).

42. Pirouzmand, F. Epidemiological trends of spine and spinal cord injuries in the largest Canadian adult trauma center from 1986 to 2006. J Neurosurg Spine, 12, 131-140 https://doi.org/10.3171/2009.9.spine0943 (2010).

43. Ning, G. Z., Wu, Q., Li, Y. L. \& Feng, S. Q. Epidemiology of traumatic spinal cord injury in Asia: a systematic review. $J$ Spinal Cord Med, 35, 229-239 https://doi.org/10.1179/2045772312y.0000000021 (2012).

\section{Tables}


Demographics of immobilized and non-immobilized patients

\begin{tabular}{|c|c|c|c|c|c|}
\hline & & $\begin{array}{l}\text { Total } \\
\mathrm{N}=759\end{array}$ & $\begin{array}{l}\text { Immobilized } \\
\mathrm{N}=438\end{array}$ & $\begin{array}{l}\text { Non-immobilized } \\
\mathrm{N}=321\end{array}$ & P-value \\
\hline \multirow[t]{3}{*}{ Country N (\%) } & $\mathrm{KR}$ & $614(80.9)$ & $362(82.6)$ & $252(78.5)$ & 0.077 \\
\hline & MY & $123(16.2)$ & $74(16.9)$ & $49(15.3)$ & \\
\hline & $\mathrm{OTH}^{\star}$ & $22(2.9)$ & $2(0.5)$ & $20(6.2)$ & \\
\hline Age median (Q1-Q3) & & $58(41-72)$ & $54(38-67)$ & $65(49-76)$ & $<0.001$ \\
\hline \multirow[t]{2}{*}{$\operatorname{Sex} N(\%)$} & Female & $339(44.7)$ & $169(38.6)$ & $170(53.0)$ & $<0.001$ \\
\hline & Male & $420(55.3)$ & $269(61.4)$ & $151(47.0)$ & \\
\hline S to $\mathrm{H}$ time (median, Q1-Q3) & & $22(15-32)$ & $22(15-33)$ & $22(15-31)$ & 0.816 \\
\hline Mechanism & Traffic & 318 (41.9) & $229(52.3)$ & $89(27.7)$ & $<0.001$ \\
\hline \multirow[t]{2}{*}{$\mathrm{N}(\%)$} & Fall & 359 (47.3) & $177(40.4)$ & $182(56.7)$ & \\
\hline & Others\# & $82(10.8)$ & $32(7.3)$ & $50(15.6)$ & \\
\hline Prehospital management (no vs. yes) & Fluid (IV, IO) & $49(6.5)$ & $43(9.8)$ & $6(1.9)$ & $<0.001$ \\
\hline \multirow[t]{4}{*}{ Location of SI N (\%) (no vs. yes) } & Cervical SI & $201(26.4)$ & $147(33.6)$ & $54(16.8)$ & $<0.001$ \\
\hline & Thoracic SI & $197(26)$ & $113(25.8)$ & $84(26.2)$ & 0.909 \\
\hline & Lumbar SI & $401(52.8)$ & $210(47.9)$ & $191(59.5)$ & 0.002 \\
\hline & $C+T / L$ & $24(3.1)$ & $22(5.0)$ & $2(0.6)$ & 0.001 \\
\hline Torso injury N (\%) (no vs. yes) & & $172(22.7)$ & $134(30.6)$ & $38(11.8)$ & $<0.001$ \\
\hline \multirow[t]{2}{*}{ RTS N (\%) } & $<7$ & $29(3.8)$ & $22(5.0)$ & $7(2.2)$ & 0.044 \\
\hline & $\geq 7$ & 730 (96.2) & $416(95.0)$ & $314(97.8)$ & \\
\hline \multirow[t]{3}{*}{ ISS N (\%) } & $<9$ & $488(64.3)$ & $248(56.6)$ & $240(74.8)$ & $<0.001$ \\
\hline & $9-15$ & $190(25.0)$ & 137 (31.3) & $53(16.5)$ & \\
\hline & $\geq 16$ & $81(10.7)$ & $53(12.1)$ & $28(8.7)$ & \\
\hline \multirow[t]{2}{*}{ Operation N (\%) (no vs. yes) } & Spine & $61(8.0)$ & $50(11.4)$ & $11(3.4)$ & $<0.001$ \\
\hline & Others! & $97(12.8)$ & 73 (16.7) & $24(7.5)$ & $<0.001$ \\
\hline \multirow[t]{2}{*}{ Favorable functional outcome $\mathrm{N}(\%)$} & Yes & $658(86.7)$ & $371(84.7)$ & $287(89.4)$ & 0.059 \\
\hline & No & $101(13.3)$ & $67(15.3)$ & $34(10.6)$ & \\
\hline Death N (\%) (no vs. yes) & & $7(0.9)$ & $3(0.7)$ & $4(1.2)$ & 0.424 \\
\hline \multicolumn{6}{|c|}{$\begin{array}{l}\text { KR, Korea; MY, Malaysia; OTH, others; S to H time, scene to hospital time; SI, spinal injury; RTS, revised trauma score; ISS, } \\
\text { Injury Severity Score. }\end{array}$} \\
\hline \multicolumn{6}{|l|}{ *Others: Japan and Vietnam. } \\
\hline \multicolumn{6}{|c|}{ \#Others: hit by person or object, choking or hanging, drowning, physical overexertion, another mechanism of injury } \\
\hline !Other operations: One patient could h & ndergone se & operation & the same ho & tal stay. & \\
\hline
\end{tabular}


Table 2

Demographic, univariable, and multivariable-adjusted logistic regression of favorable and unfavorable functional outcomes in patients

\begin{tabular}{|c|c|c|c|c|c|c|c|}
\hline & & $\begin{array}{l}\text { Favorable } \\
\text { functional } \\
\text { outcome }\end{array}$ & $\begin{array}{l}\text { Unfavorable } \\
\text { functional } \\
\text { outcome }\end{array}$ & $\begin{array}{l}\text { Univariable } \\
\text { OR }(95 \% \mathrm{Cl})\end{array}$ & $\begin{array}{l}\text { Univariable } \\
\text { P-value }\end{array}$ & $\begin{array}{l}\text { Multivariable } \\
\text { OR }(95 \% \mathrm{Cl})\end{array}$ & $\begin{array}{l}\text { Multivariable } \\
\text { P-value }\end{array}$ \\
\hline & & $N=658$ & $N=101$ & & & & \\
\hline \multirow[t]{3}{*}{ Country N (\%) } & $\mathrm{KR}$ & $\begin{array}{l}551 \\
(83.7)\end{array}$ & $63(62.4)$ & ref & ref & ref & ref \\
\hline & MY & 89 (13.5) & 34 (33.7) & $\begin{array}{l}0.30 \\
(0.19-0.48)\end{array}$ & $<0.001$ & $\begin{array}{l}0.37 \\
(0.20-0.71)\end{array}$ & 0.002 \\
\hline & $\mathrm{OTH}^{\star}$ & $18(2.7)$ & $4(4.0)$ & $\begin{array}{l}0.52 \\
(0.17-1.57)\end{array}$ & 0.242 & $\begin{array}{l}0.57 \\
(0.16-1.99)\end{array}$ & 0.376 \\
\hline $\begin{array}{l}\text { Age (median, } \\
\text { Q1-Q3) }\end{array}$ & & $\begin{array}{l}59 \\
(43-72.3)\end{array}$ & $\begin{array}{l}52 \\
(34.5-65)\end{array}$ & $\begin{array}{l}1.02 \\
(1.01-1.03)\end{array}$ & 0.002 & $\begin{array}{l}1.00 \\
(0.98-1.01)\end{array}$ & 0.777 \\
\hline \multirow[t]{2}{*}{ Sex N (\%) } & female & $\begin{array}{l}308 \\
(46.8)\end{array}$ & 31 (30.7) & ref & ref & ref & ref \\
\hline & male & $\begin{array}{l}350 \\
(53.2)\end{array}$ & 70 (69.3) & $\begin{array}{l}0.50 \\
(0.32-0.79)\end{array}$ & 0.003 & $\begin{array}{l}0.76 \\
(0.46-1.27)\end{array}$ & 0.296 \\
\hline $\begin{array}{l}\text { S to H time } \\
\text { (median, Q1- } \\
\text { Q3) }\end{array}$ & & $\begin{array}{l}22 \\
(15.8-31)\end{array}$ & $\begin{array}{l}23 \\
(14-34.5)\end{array}$ & $\begin{array}{l}1.00 \\
(0.99-1.01)\end{array}$ & 0.992 & & \\
\hline Mechanism & traffic & $\begin{array}{l}265 \\
(40.3)\end{array}$ & $53(52.5)$ & Ref & ref & & \\
\hline \multirow[t]{2}{*}{$\mathrm{N}(\%)$} & Fall & $\begin{array}{l}319 \\
(48.5)\end{array}$ & $40(39.6)$ & $\begin{array}{l}1.6 \\
(1.03-2.48)\end{array}$ & 0.38 & & \\
\hline & Others\# & 74 (11.2) & $8(7.9)$ & $\begin{array}{l}1.85 \\
(0.84-4.06)\end{array}$ & 0.13 & & \\
\hline $\begin{array}{l}\text { Prehospital } \\
\text { management } \\
\mathrm{N}(\%) \text { (no vs. } \\
\text { yes) }\end{array}$ & $\begin{array}{l}\text { Fluid (IV, } \\
\text { IO) }\end{array}$ & $29(4.4)$ & $20(19.8)$ & $\begin{array}{l}5.36 \\
(2.90-9.91)\end{array}$ & $<0.001$ & $\begin{array}{l}0.39 \\
(0.19-0.84)\end{array}$ & 0.016 \\
\hline $\begin{array}{l}\text { Location of SI } \\
N(\%)\end{array}$ & $\begin{array}{l}\text { Cervical } \\
\text { SI }\end{array}$ & $\begin{array}{l}168 \\
(25.5)\end{array}$ & 33 (32.7) & $\begin{array}{l}0.69 \\
(0.41-1.16)\end{array}$ & 0.158 & & \\
\hline \multirow[t]{3}{*}{ (no vs. yes) } & $\begin{array}{l}\text { Thoracic } \\
\text { SI }\end{array}$ & $\begin{array}{l}173 \\
(26.3)\end{array}$ & $24(23.8)$ & $\begin{array}{l}1.24 \\
(0.67-2.31)\end{array}$ & 0.493 & & \\
\hline & $\begin{array}{l}\text { Lumbar } \\
\text { SI }\end{array}$ & $\begin{array}{l}357 \\
(54.3)\end{array}$ & $44(43.6)$ & $\begin{array}{l}1.87 \\
(1.17-2.99)\end{array}$ & 0.009 & $\begin{array}{l}1.07 \\
(0.67-1.72)\end{array}$ & 0.772 \\
\hline & $C+T L S$ & $21(3.2)$ & $3(3.0)$ & $\begin{array}{l}1.08 \\
(0.32-3.68)\end{array}$ & 0.906 & & \\
\hline
\end{tabular}

KR, Korea; MY, Malaysia; OTH, others; S to H time, scene to hospital time; SI, spinal injury; RTS, revised trauma score; ISS, Injury Severity Score.

*Others: Japan and Vietnam.

\#Others: hit by person or objects, choking or hanging, drowning, physical overexertion, another mechanism of injury

!Other operations: One patient could have undergone several operations during the same hospital stay. 


\begin{tabular}{|c|c|c|c|c|c|c|c|}
\hline & & $\begin{array}{l}\text { Favorable } \\
\text { functional } \\
\text { outcome }\end{array}$ & $\begin{array}{l}\text { Unfavorable } \\
\text { functional } \\
\text { outcome }\end{array}$ & $\begin{array}{l}\text { Univariable } \\
\text { OR }(95 \% \mathrm{Cl})\end{array}$ & $\begin{array}{l}\text { Univariable } \\
\text { P-value }\end{array}$ & $\begin{array}{l}\text { Multivariable } \\
\text { OR }(95 \% \mathrm{Cl})\end{array}$ & $\begin{array}{l}\text { Multivariable } \\
\text { P-value }\end{array}$ \\
\hline & & $N=658$ & $\mathbf{N}=101$ & & & & \\
\hline \multicolumn{2}{|l|}{$\begin{array}{l}\text { Torso injury N } \\
\text { (\%) (no vs. } \\
\text { yes) }\end{array}$} & $\begin{array}{l}137 \\
(20.8)\end{array}$ & $35(34.7)$ & $\begin{array}{l}0.50 \\
(0.32-0.78)\end{array}$ & 0.002 & $\begin{array}{l}1.13 \\
(0.63-2.02)\end{array}$ & 0.683 \\
\hline Immobilization & no & $\begin{array}{l}287 \\
(43.6)\end{array}$ & $34(33.7)$ & ref & ref & ref & ref \\
\hline $\mathrm{N}(\%)$ & yes & $\begin{array}{l}371 \\
(56.4)\end{array}$ & $67(67.3)$ & $\begin{array}{l}0.66 \\
(0.42-1.02)\end{array}$ & 0.061 & $\begin{array}{l}1.06 \\
(0.62-1.81)\end{array}$ & 0.826 \\
\hline \multirow[t]{2}{*}{ RTS N (\%) } & $<7$ & $17(2.6)$ & 12 (11.9) & ref & ref & ref & ref \\
\hline & $\geq 7$ & $\begin{array}{l}641 \\
(97.4)\end{array}$ & $89(88.1)$ & $\begin{array}{l}5.08 \\
(2.35-11.00)\end{array}$ & $<0.001$ & $\begin{array}{l}3.41 \\
(1.41-8.25)\end{array}$ & 0.007 \\
\hline \multirow[t]{3}{*}{ ISS N (\%) } & $<9$ & $\begin{array}{l}450 \\
(68.4)\end{array}$ & $38(37.6)$ & ref & ref & ref & ref \\
\hline & $9-15$ & $\begin{array}{l}150 \\
(22.8)\end{array}$ & $40(39.6)$ & $\begin{array}{l}0.32 \\
(0.20-0.51)\end{array}$ & $<0.001$ & $\begin{array}{l}0.41 \\
(0.24-0.72)\end{array}$ & 0.002 \\
\hline & $\geq 16$ & $58(8.8)$ & $23(22.8)$ & $\begin{array}{l}0.21 \\
(0.12-0.38)\end{array}$ & $<0.001$ & $\begin{array}{l}0.35 \\
(0.17-0.72)\end{array}$ & 0.004 \\
\hline \multirow{2}{*}{$\begin{array}{l}\text { Operation N } \\
(\%) \text { (no vs. } \\
\text { yes) }\end{array}$} & Spine & $39(5.9)$ & $22(21.8)$ & $\begin{array}{l}0.23 \\
(0.13-0.40)\end{array}$ & $<0.001$ & $\begin{array}{l}0.21 \\
(0.11-0.41)\end{array}$ & $<0.001$ \\
\hline & Others! & $75(11.4)$ & $22(21.8)$ & $\begin{array}{l}0.46 \\
(0.27-0.79)\end{array}$ & $<0.001$ & $\begin{array}{l}0.89 \\
(0.47-1.68)\end{array}$ & 0.715 \\
\hline \multicolumn{8}{|c|}{$\begin{array}{l}\text { KR, Korea; MY, Malaysia; OTH, others; S to H time, scene to hospital time; SI, spinal injury; RTS, revised trauma score; ISS, } \\
\text { Injury Severity Score. }\end{array}$} \\
\hline \multicolumn{8}{|c|}{ *Others: Japan and Vietnam. } \\
\hline \multicolumn{8}{|c|}{ \#Others: hit by person or objects, choking or hanging, drowning, physical overexertion, another mechanism of injury } \\
\hline
\end{tabular}

\section{Figures}




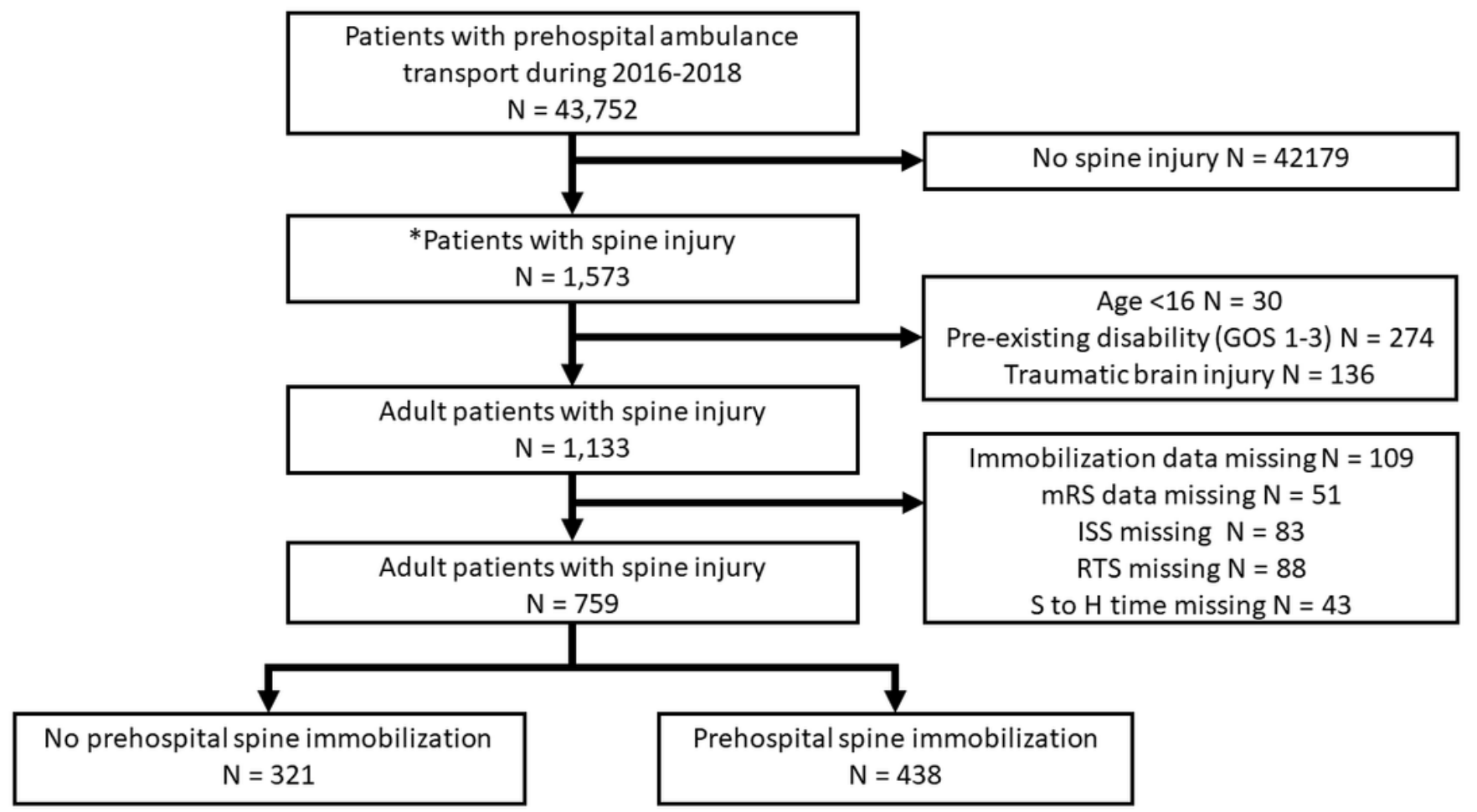

Figure 1

Flow diagram of patients included in our study GOS, Glasgow outcome scale; mRS, modified Rankin Scale; RTS, revised trauma score; StoH time, Scene-to-hospital time *Patients with spinal injury were defined as meeting the diagnosis of ICD-9 or 10 described in the methods.

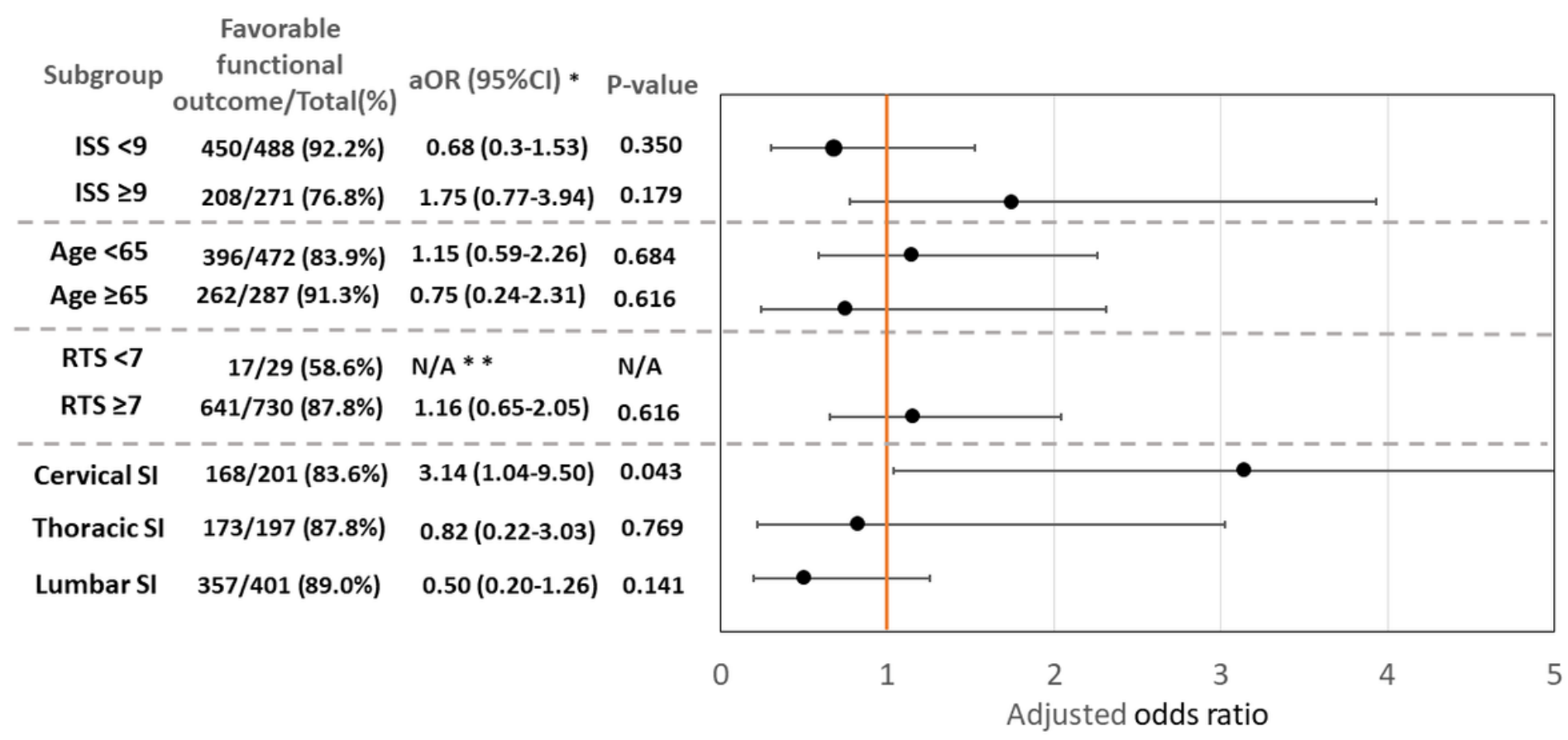




\section{Figure 2}

Subgroup analysis for favorable neurologic outcome, ISS $<9$, ISS $\geq 9$, age $\geq 65$, age $<65$, adjusted multiple logistic regression aOR, adjusted odds ratio; SI, spinal injury. *All subgroups except RTS <7 were adjusted by country, age, sex, scene-to-hospital time, mechanism, prehospital fluid management, cervical spinal injury, thoracic spinal injury, lumbar spinal injury, torso injury, revised trauma score, ISS, received spine operation, and received other operations. **Due to the small subgroup size, multivariable logistic regression was not applicable. 